\title{
Rancang Bangun Aplikasi Peringatan Dan Mitigasi Gempa Bumi Berbasis Mobile Hybrid
}

\author{
Ida Bagus Gede Purwania ${ }^{1}$, Rukmi Sari Hartati ${ }^{2}$, Yoga Divayana ${ }^{3}$ \\ [Submission: 09-09-2020, Accepted: 17-12-2020]
}

\begin{abstract}
BMKG and BNBP are organizations formed by the government to handle disasters both before, pre-disaster and after a disaster occurs. BMKG and BNBP have several early warning systems, but it requires a long and long process for information to reach the community. This research was conducted to produce applications that can provide warnings to the community when an earthquake occurs and can provide information on the nearest evacuation site. Also this application is designed to be able to connect with friends or close relatives when an earthquake disaster occurs. The application will send notifications automatically to friends or close relatives when the user is affected by an earthquake. This Earthquake Warning and Mitigation application was developed based on mobile hybrids by utilizing open source earthquake data from InaSAFE and integrated with the Google Maps API.
\end{abstract}

Intisari-BMKG dan BNBP merupakan organisasi yang dibentuk pemerintah untuk menangani bencana baik sebelum, pra-bencana maupun setelah bencana terjadi. BMKG dan BNBP memiliki beberapa sistem peringatan dini, tetapi membutuhkan proses yang cukup lama dan panjang agar informasi sampai di masyarakat. Penelitian ini dilakukan untuk menghasilkan aplikasi yang dapat memberikan peringatan ke masyarakat ketika terjadi gempa bumi dan memberikan informasi lokasi evakuasi yang terdekat. Selain itu aplikasi ini dirancang agar dapat terhubung dengan teman atau kerabat dekat saat terjadi bencana gempa bumi. Notifikasi secara otomatis akan dikirimkan melalui aplikasi ke teman atau kerabat dekat ketika pengguna terdampak bencana gempa bumi. Aplikasi Peringatan dan Mitigasi Gempa Bumi ini dikembangkan berbasis mobile hybrid dengan memanfaatkan data open source gempa bumi dari InaSAFE dan terintegrasi dengan Google Maps API.

Kata Kunci- Sistem Peringatan Dini, Aplikasi Mitigasi Gempa Bumi, Mobile Hybrid, Google Maps API, InaSAFE

\section{PENDAHULUAN}

Gempa bumi merupakan getaran yang terjadi karena terlepasnya energi secara tiba-tiba dalam batuan yang mengalami deformasi di dalam bumi [1]. Indonesia adalah salah satu negara yang rawan mengalami gempa bumi karena diapit oleh dua benua, dua samudera, dan tiga lempeng yang membentuk bumi.

\footnotetext{
${ }^{1}$ Mahasiswa, Program Pasca Sarjana, Manajemen Sistem Informasi dan Komputer Fakultas Teknik Universitas Udayana, Jln. P.B. Sudirman, Denpasar, Bali 80232 INDONESIA (tlp: 0361-239599; e-mail: guspurwania@gmail.com)

2, 3 Dosen, Program Pasca Sarjana, Magister Teknik Elektro Fakultas Teknik Universitas Udayana, Jln. P.B. Sudirman, Denpasar, Bali 80232 INDONESIA (tlp: 0361-239599; e-mail: ${ }^{2}$ rukmisari@unud.ac.id, ${ }^{3}$ yoga@unud.ac.id)
}

Indonesia memiliki keaktifan gempa bumi yang sangat tinggi Berdasarkan data dari BNBP (Badan Nasional Penanggulangan Bencana), pada Agustus 2010 sampai Januari 2015 tercatat 1160 kali gempa bumi yang terjadi di seluruh Indonesia yang memiliki kekuatan lebih dari 4 SR (Skala Richter), dimana kekuatan gempa tersebut bersifat merusak dan dapat menyebabkan korban jiwa [2].

Penyediaan sistem informasi di Indonesia terkait dengan gempa bumi merupakan inovasi yang sangat dibutuhkan oleh masyarakat, agar masyarakat dapat melakukan upaya tanggap darurat atau mitigasi jika terjadi gempa bumi. Pada tahun 2005, Indonesia dan 16 institusi termasuk BMKG yang didukung oleh beberapa negara mengembangkan sistem untuk peringatan dini tsunami yang diberi nama "Indonesia Tsunami Early Warning System (Ina TEWS)". Tujuan dari dikembangkannya sistem ini adalah untuk mengurangi resiko akibat tsunami melalui pemberitahuan dan peringatan terjadinya bencana tsunami beberapa saat setelah terjadinya gempa bumi [3].

Berdasarkan SOP BMKG mengenai standar pengiriman informasi pemberitahuan dan peringatan dini tsunami dan gempa bumi, dalam pengiriman informasi peringatan dini bencana ke masyarakat melalui media perantara atau media massa seperti TV, radio, website, atau instansi-instansi terkait, setidaknya membutuhkan waktu lebih dari 5 menit [3]. Bagi masyarakat terutama yang bekerja, agak susah untuk mendapatkan informasi tersebut karena kesibukannya. Selain itu orang yang terdampak oleh gempa bumi akan merasa panik dan tidak tahu harus melakukan tindakan apa. Keluarga korban yang terdampak gempa bumi juga merasakan ketakutan yang sama ketika tidak tahu keadaan keluarganya. Masalah tersebut perlu diatasi dengan mengembangkan aplikasi peringatan, pemberitahuan dan mitigasi gempa bumi berbasis mobile agar informasi tersebut dapat diakses secara luas. Aplikasi ini dapat memberikan peringatan dini gempa bumi dan mitigasi jalur evakuasinya, serta dapat memberikan informasi tentang keadaaan kerabat ataupun teman yang terdampak bencana gempa bumi.

\section{STATE OF THE ART}

Perkembangan teknologi informasi dewasa ini berkembang sangat cepat. Teknologi informasi dapat diimplementasikan dalam berbagai bidang kehidupan, baik di bidang pendidikan, perekonomian, riset, geologi, telekomunikasi dan bidang lainnya. Masyarakat dapat mengetahui banyak informasi dengan lebih cepat dengan menggunakan internet. Melalui penggunaan akses internet masyarakat juga lebih mudah dalam mencari dan mengetahui banyak hal kapan saja dan dimana saja. 
Indonesia dalam beberapa tahun terakhir ini sering diguncang dengan bencana alam, khususnya gempa bumi. Gempa bumi terjadi dari skala kecil bahkan sampai skala besar hingga menyebabkan terjadinya tsunami yang akhirnya menelan banyak korban jiwa. Sistem dan informasi tentang bencana ataupun mitigasi terhadap datangnya bencana sangat diperlukan. Meminimalisir dampak dari terjadinya bencana merupakan prioritas bagi negara-negara rawan bencana, termasuk Indonesia sendiri [4].

USGS adalah lembaga survei di Amerika yang menangani bidang geologi. USGS melakukan penelitian tentang sistem pemberitahuan dan peringatan dini bencana yang diimplementasikan di daerah pantai barat Amerika. Sistem yang dikembangkan bernama ShakeAlert. Penelitian ini menjelaskan bahwa sistem peringatan dini ini sangat dibutuhkan untuk menminimalisir dampak dari gempa bumi seperti jatuhnya korban jiwa. ShakeAlert dibangun dari 2006 dan dioperasikan tahun 2012 oleh CISN (Lembaga Jaringan Seismik Terintegrasi di California) untuk memantau terjadinya gempa bumi di wilayah tersebut. Cara kerja sistem ShakeAlert yaitu pengguna akan menerima informasi peringatan gempa bumi berupa visual ataupun audio melalui aplikasi komputer seperti yang ditunjukkan pada Gambar 1, ketika terjadi gempa bumi maka akan muncul peta pada sistem dan menunjukkan titik pusat gempa dan radiusnya [5][6].

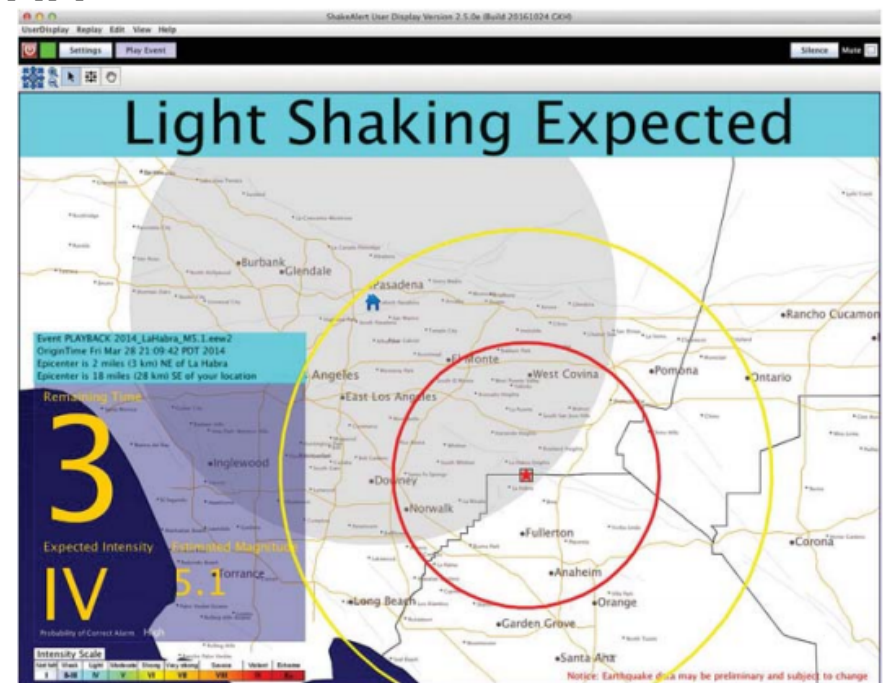

Gambar 1: User Interface ShakeAlert

ShakeAlert merupakan salah satu sistem yang menerapkan teknologi SIG (Sistem Informasi Geografis). Sistem Informasi Geografis adalah sistem informasi berbasis pemetaan, dimana data yang diolah adalah data spasial. Pada buku Eko Budiyanto, SIG didefinisikan sebagai sebuah sistem komputer untuk mengumpulkan, memeriksa, mengintegrasikan, dan menganalisa informasi yang berkaitan dengan permukaan bumi [7]. Sistem informasi geografis dapat dimanfaatkan dan diimplementasikan pada sistem peringatan dan penangggulangan bencana, seperti memberikan lokasi atau koordinat terjadinya bencana, navigasi ke lokasi evakuasi atau pengungsian sehingga dapat meminimalisir resiko terjadinya bencana [8].

Penelitian lain tentang sistem informasi geografis dilakukan oleh Rika Dwi Kurniasih dengan mengembangkan sistem untuk memanajemen rute evakuasi bencana tsunami di Kota Palu. Sistem ini membantu masyarakat di Kota Palu untuk menemukan rute evakuasi terdekat ketika terjadi bencana tsunami. Kekurangan dari sistem ini adalah batasan geografis yang hanya menampilkan tempat evakuasi di Kota Palu saja, serta tidak menampilkan daerah ancaman dan resiko bencana [9]. Penelitian ini perlu dikembangkan agar dapat diimplementasikan di wilayah lain, dan dapat menampilkan daerah ancaman dan resiko bencana sehingga masyarakat mengetahui mitigasi yang harus dilakukan.

Indonesia juga mengembangkan sistem penerima peringatan atau WRS (Warning Receiver System) yang digunakan untuk menyebarkan informasi gempa bumi dan peringatan dini tsunami kepada lembaga perantara, media massa dan instansi terkait. Jadi pada sistem penerima peringatan ini terdapat sistem server dan client, dimana sistem server bertugas untuk mengirim informasi, dan sistem client bertugas untuk menerima informasi dari server. Sistem server dikelola oleh BMKG, dan sistem client dikelola oleh lembaga perantara atau instansi seperti misalnya pemerintah daerah, provinsi, atau kabupaten. Diagram pada Gambar 2 menggambarkan cara kerja antara BMKG dengan lembaga-lembaga perantara pada aplikasi WRS [10].

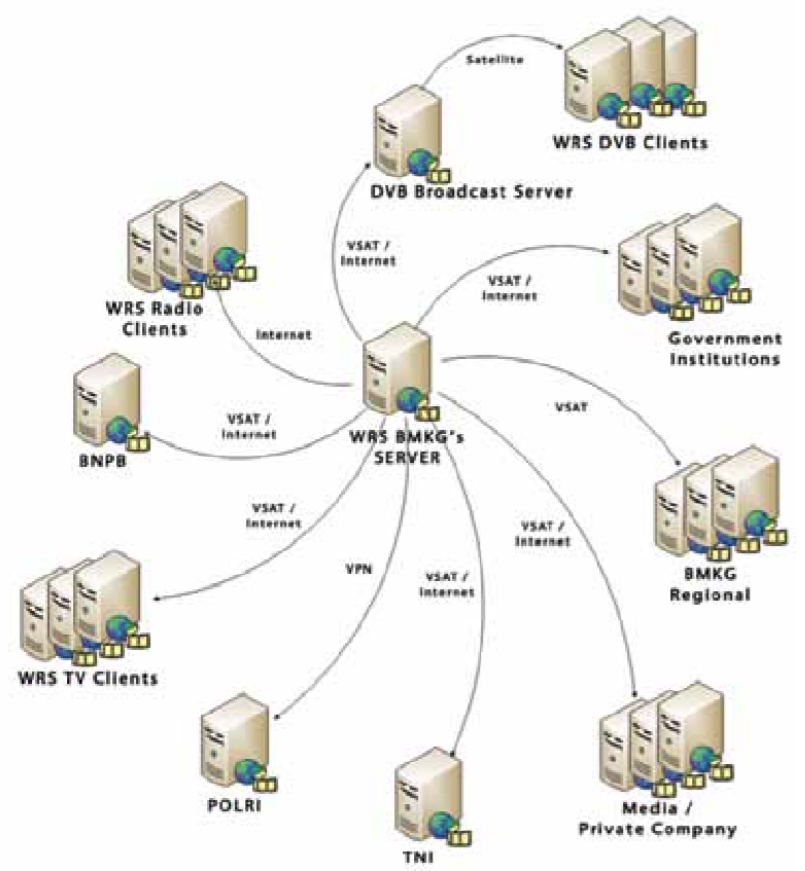

Gambar 2: Hubungan antar lembaga dalam diseminasi via WRS

Aplikasi WRS dilengkapi beberapa layanan seperti alarm yang mengeluarkan suara khusus saat sistem menerima infromasi gempa bumi atau peringatan dini tsunami. Selain itu aplikasi WRS juga dilengkapi dengan SMS Forwarder, Web SIG dan informasi BMKG seperti cuaca/iklim. Aplikasi WRS ini memerlukan waktu yang sangat lama agar peringatan gempa maupun tsunami sampai di end user (masyarakat) karena pemerintah mempunyai SOP (Standard Operation Procedure) tersendiri untuk melakukan pengiriman peringatan gempa dan tsunami, yang harus melalui atau masuk ke perantara/client terlebih dahulu.

Berdasarkan analisa penelitian yang terkait dan melihat keunggulan dan kekurangan dari penelitian tersebut maka 
aplikasi peringatan dan mitigasi gempa akan dikembangkan diatas platform mobile untuk mobilitas pengguna, dengan mengintegrasikan Google Maps API untuk sistem informasi pemetaan lokasi gempa dan navigasi ke tempat evakuasi, sedangkan data gempa bumi didapatkan melalui API InaSAFE. Proyek InaSAFE dimulai dengan tujuan untuk menyediakan alat bagi para manajer penanggulangan bencana yang ingin mempelajari potensi dampak dari suatu bencana [11]. Salah satu faktor yang berpengaruh dalam menggunakan tools InaSAFE ini adalah akses terbuka terhadap data yang relevan, terbaru dan data geospasial yang dikelola secara baik. Aplikasi peringatan dini dan mitigasi gempa dibangun menggunakan teknologi Hybrid Application yaitu kombinasi antara pengembangan Native Application dan Web Application. Hybrid Application adalah aplikasi yang dapat dijalankan lintas platform (cross platform). Gambar 3 menggambarkan kemampuan (capability) dari masing-masing pengembangan aplikasi [12].

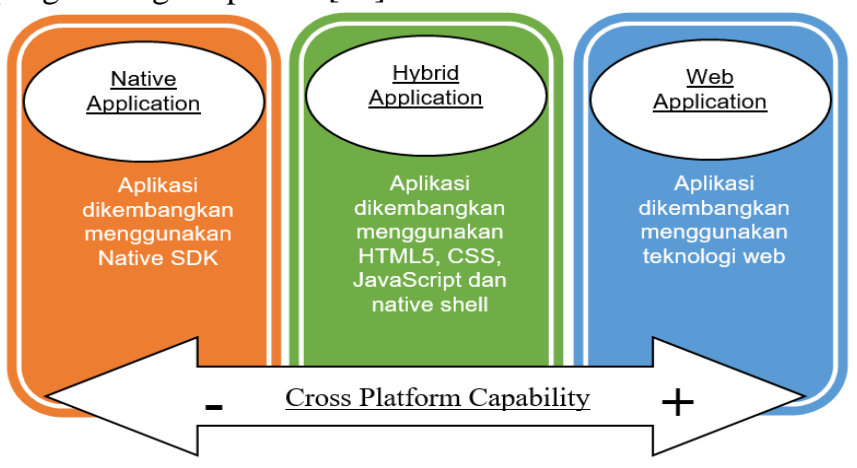

Gambar 3: Cross Platform Capability

Pengembangan Native Application seperti yang ditunjukkan Gambar 3 membutuhkan kemampuan dan pengetahuan yang tinggi dalam native programming, misalnya saat mengembangkan Native Application untuk iPhone maka harus menguasai Bahasa Pemrograman Swift atau Objective-C, sedangkan jika ingin mengembangkan Aplikasi Android harus memiliki kemampuan dalam Bahasa Pemrograman Java, oleh karena itu pengembangan Aplikasi peringatan dini dan mitigasi gempa bumi ini dikembangkan menggunakan Hybrid Application karena lebih efektif dan efisien serta dapat dijalankan di berbagai platform (cross platform) dengan satu Bahasa pemrograman yaitu HTML5, CSS3 dan JavaScript [13][14].

\section{MODEL SISTEM}

Model sistem menggambarkan elemen-elemen infrastruktur yang digunakan dalam pengembangan sistem atau aplikasi, dimana elemen-elemen tersebut saling terhubung, terintegrasi, dan saling mendukung satu sama lain untuk membentuk sebuah sistem. Gambaran model infrastruktur dari Aplikasi Peringatan, Pemberitahuan dan Mitigasi Gempa Bumi berbasis mobile ini ditunjukkan pada Gambar 4

I.B. Gd. Purwania: Rancang Bangun Aplikasi Peringatan ...

\footnotetext{
I.B. Gd. Purwania: Rancang Bangun Aplikasi Peringa
}

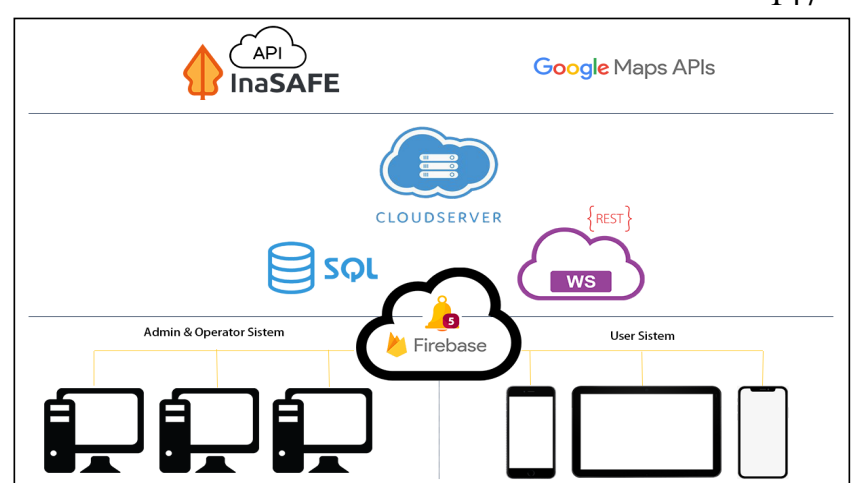

Gambar 4: Model Infrastruktur Aplikasi Peringatan dan Mitigasi Gempa Bumi

Infrastruktur system terbagi atas beberapa layer diantaranya adalah Layer API, Server, Database, Notification dan Application. Pada Layer API, sistem ini menggunakan dua API yaitu API InaSAFE dan Google Maps API. InSAFE API digunakan untuk menarik data gempa bumi dalam bentuk JSON. Google Maps API digunakan untuk mengintegrasikan data koordinat gempa bumi, tempat evakuasi dan jalur evakuasi yang divisualisasikan dalam bentuk maps/peta [15]. Layer Server adalah layer yang bertugas untuk menyimpan seluruh data/storage dan menjalankan service yang diperlukan untuk menjalankan aplikasi [16]. Sistem ini menggunakan Database SQL dan REST Web Service yang terdapat pada Layer Database. REST Web Service menjadi jembatan/penghubung antara data dengan aplikasi client [17]. Layer selanjutnya adalah Notification yang bertugas untuk mengirim push notification ke end user. Sistem ini menggunakan Firebase Notification untuk mengirimkan notifikasi. Application Layer dibagi menjadi dua yaitu aplikasi yang dikelola oleh admin/operator dan aplikasi untuk user/masyarakat.

\section{IV.IMPLEMENTASI}

Tahapan implementasi Aplikasi Peringatan, Pemberitahuan dan Mitigasi Gempa Bumi ini dibagi menjadi implementasi algoritma yang digunakan dalam pengembangan aplikasi, metode pengembangan aplikasi dan uji coba aplikasi.

\section{A. Implementasi Algoritma}

Algoritma yang diimplementasikan pada Aplikasi Peringatan, Pemberitahuan dan Mitigasi Gempa Bumi ini adalah Round-Robin Scheduling dan Haversine Formula. Round-Robin Scheduling digunakan untuk penjadwalan pengecekan API InaSAFE dan menjalankan proses menggunakan queue. Haversine Formula digunakan untuk menentukan radius terdekat dengan gempa dan jarak terdekat ke tempat evakuasi.

1) Round-Robin Scheduling adalah algoritma penjadwalan proses berdasarkan jatah waktu pemroses atau kwanta [18]. Ketika jatah waktu habis dan masih ada proses yang belum selesai, maka pemrroses akan dialihkan ke proses lain tetapi jika tidak ada proses lain maka proses diakhiri. Konsep dasar dari algoritma ini adalah dengan menggunakan time-sharing. 
Round-Robin Scheduling digunakan pada aplikasi ini untuk mengecek gempa bumi pada API InaSAFE dan menjalankan beberapa proses sesuai dengan kondisi yang terpenuhi seperti mengirimkan notifikasi gempa ke user yang berada pada radius gempa

2) Haversine Formula adalah perhitungan yang digunakan untuk navigasi. Haversine Formula menggunakan jarak antara dua titik pada permukaan bumi berdasarkan bujur dan lintang (radius). Perhitungan pada formula ini mengabaikan efek ellipsoidal atau bumi tidak bulat sempurna tetapi mendekati bentuk telur dengan permukaan tidak rata [19]. Haversine Formula digunakan untuk menghitung jarak antara dua titik koordinat, yaitu titik GPS user dan titik tempat evakuasi. Titik ini memiliki nilai latitude dan longitude, sehingga dapat digunakan sebagai perbandingan jarak untuk penentuan lokasi evakuasi terdekat.

\section{B. Metodologi Pengembangan Aplikasi}

Metodologi pengembangan aplikasi terdiri dari beberapa langkah, yaitu pengumpulan data atau informasi dan perancangan sistem. Teknik pengumpulan data menggunakan wawancara, observasi secara langsung dan studi literatur, sedangkan metode pengembangan sistem mengadopsi pendekatan Waterfall [20].

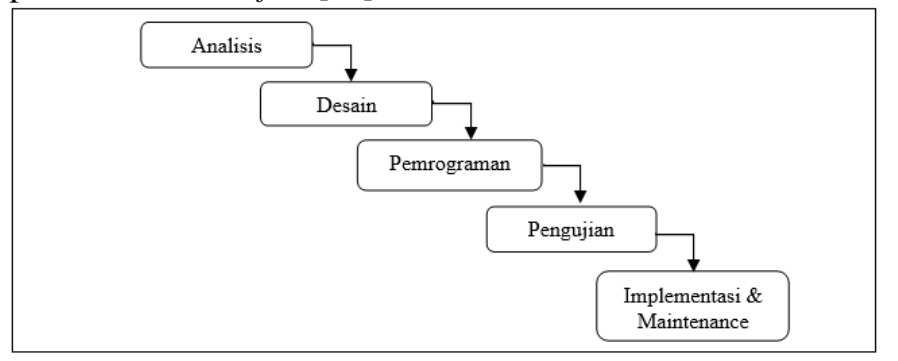

Gambar 5: Pendekatan Waterfall

Model Waterfall adalah salah satu metode pengembangan sistem atau perangkat lunak yang bersifat berurutan atau sekuensial seperti yang ditunjukkan pada Gambar 5. Tahapan perancangan Aplikasi Peringatan, Pemberitahuan dan Mitigasi Gempa Bumi berbasis mobile hybrid adalah sebagai berikut.

1) Tahapan Analisis merupakan tahapan untuk menganalisa permasalahan dan mencari solusi serta data dari permasalahan terkait dengan melakukan penelitian dan pengumpulan data. Sumber data yang diperoleh berdasarkan observasi lapangan dan wawancara langsung ke pihak-pihak, dinas terkait dan masyarakat, serta referensi dari buku, jurnal, artikel dan situs web

2) Tahapan Desain merupakan tahapan untuk merancang atau menggambarkan alur sistem secara keseluruhan menggunakan beberapa metode pemodelan sistem.

3) Tahapan Pemrograman merupakan tahapan untuk menerjemahkan hasil desain (alur sistem dan wireframe) ke dalam bahasa pemrograman. Bahasa Pemrograman yang digunakan adalah PHP, HTML5, CSS3, JavaScript dan VueJS dengan menggunakan Framework PhoneGap/Cordova dan Onsen UI untuk membangun Hybrid Application.

4) Tahapan Pengujian merupakan tahapan untuk menguji kelayakan suatu sistem. Pengujian dibagi menjadi dua jenis yaitu pengujian yang dilakukan oleh pengembang dan pengujian yang dilakukan oleh pengguna awam (sasaran pengguna aplikasi). Pengujian oleh pengembang dilakukan untuk membenahi bug/masalah yang terjadi pada aplikasi, sedangkan pengujian oleh pengguna awam dilakukan untuk menunjukkan kelayakan aplikasi baik dari segi tampilan (user interface), fitur yang disediakan dan informasi yang diberikan oleh aplikasi/sistem.

5) Tahapan Implementasi merupakan tahapan dimana sistem sudah siap untuk diproduksi dan digunakan, pada tahap ini juga dilakukan maintenance (pemeliharaan) sistem untuk mengurangi kesalahan-kesalahan kecil yang terjadi pada sistem, serta mengurangi data junk (sampah) yang membebani sistem (database maintenance). Versioning (upgrade) juga dilakukan pada tahap ini untuk meningkatkan fitur dan kinerja sistem supaya menjadi lebih baik.

\section{Uji Coba Aplikasi}

Pengujian Aplikasi Peringatan, Pemberitahuan dan Mitigasi Gempa berbasis mobile hybrid ini dibagi berdasarkan fiturfitur utama aplikasi diantaranya adalah Fitur Informasi Gempa Bumi, Fitur Peringatan Gempa Bumi, Fitur Panic dan Safe Button, Fitur Tempat Evakuasi Terdekat, Fitur Navigasi ke Tempat Evakuasi dan Fitur untuk mengetahui keadaan teman atau kerabat dekat yang terdampak gempa bumi.

1) Fitur Informasi Gempa Bumi: Pengguna dapat mengakses informasi gempa bumi yang terjadi dan terkini pada aplikasi ini. Uji coba fitur informasi gempa bumi pada aplikasi ini yaitu dengan cara mengikuti langkah-langkah berikut.

a) Pengguna melakukan login ke sistem dengan cara menginputkan nomer telepon dan Kode OTP seperti pada Gambar 6.

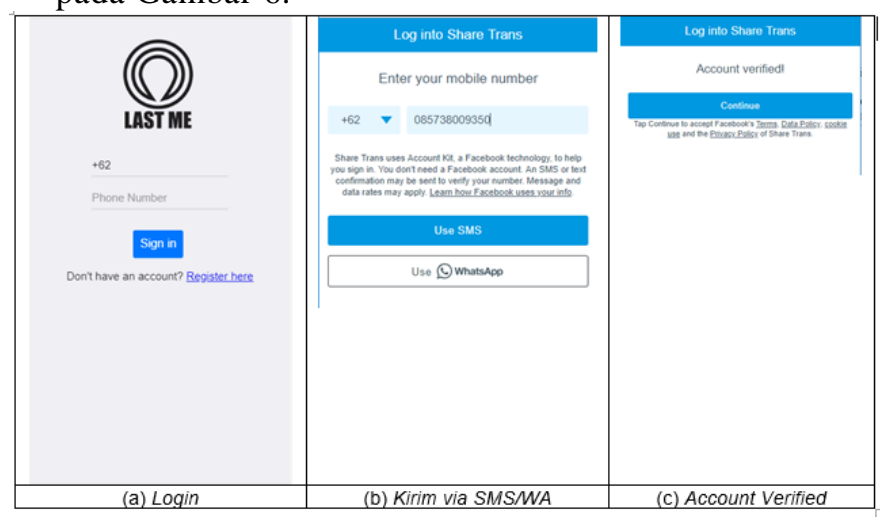

Gambar 6: Login ke Aplikasi

b) Jika Nomer Telepon dan Kode OTP valid maka pengguna diarahkan ke halaman dashboard. Pada halaman ini terdapat data update informasi terkini tentang gempa bumi.

2) Fitur Peringatan Gempa Bumi: Aplikasi ini dapat memberikan notifikasi peringatan dini gempa bumi kepada pengguna. Uji coba fitur peringatan gempa bumi pada aplikasi ini yaitu sebagai berikut.

a) Aplikasi ini memiliki proses scheduler yang berjalan di background service. Proses scheduler ini bertujuan untuk mengecek API InaSAFE, jika sistem mendapatkan response terjadinya gempa bumi dari $A P I$ 
InaSAFE maka sistem akan mengecek pengguna/user yang berada di radius gempa bumi tersebut dan mengirimkan broadcast notification.

b) Jika lokasi pengguna/user berada dalam radius gempa bumi maka pengguna aplikasi akan mendapatkan notifikasi seperti pada Gambar 7.

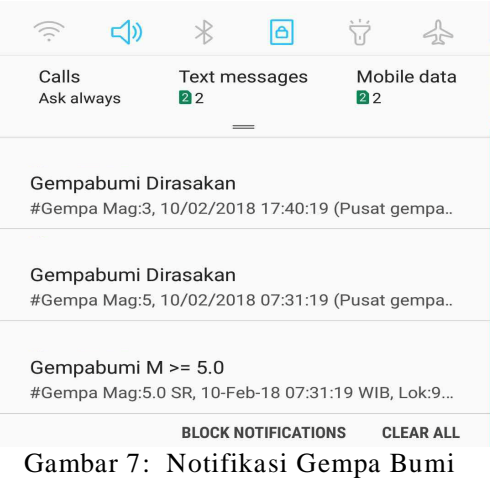

3) Fitur Panic dan Safe Button: Saat terjadi gempa bumi, aplikasi ini memberikan action yaitu panic dan safe. Panic berarti pengguna dalam keadaan darurat, sedangkan safe berarti pengguna dalam keadaan aman. Fitur ini sangat berguna untuk menginformasikan keadaan ke teman atau kerabat dekat. Gambar 8 menunjukkan tombol action panic dan safe.

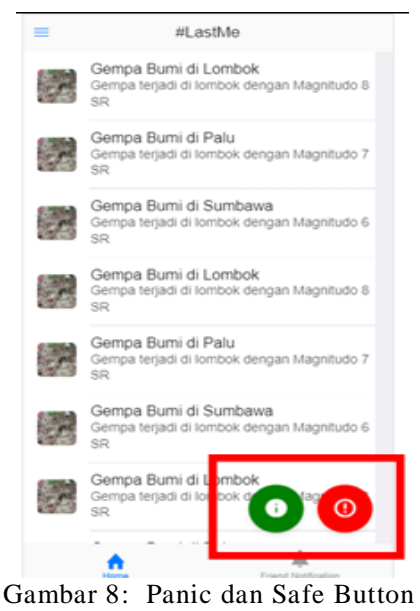

Tombol berwarna hijau adalah safe button, sedangkan tombol berwarna meran adalah panic button. Saat tombol tersebut ditekan, maka aplikasi akan secara otomatis mengirimkan notifikasi ke semua friend list.

4) Fitur Navigasi ke Tempat Evakuasi Terdekat: Aplikasi ini dilengkapi dengan fitur tempat evakuasi saat terjadi gempa bumi, serta fitur navigasi ke tempat evakuasi tersebut. Uji coba fitur tempat evakuasi pada aplikasi ini yaitu sebagai berikut.

a) Pada Aplikasi masuk ke Menu "Evakuasi" seperti pada Gambar 9.

I.B. Gd. Purwania: Rancang Bangun Aplikasi Peringatan ...

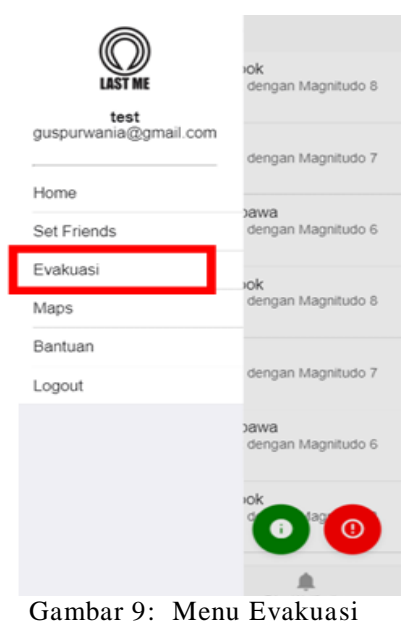

b) Pengguna/user akan diarahkan ke halaman evakuasi. Halaman ini dalam bentuk maps (peta) dan terdapat marker yang menunjukkan tempat evakuasi seperti yang terlihat pada Gambar 10. Untuk mencari tempat evakuasi terdekat klik tombol marker yang berada pada bagian bawah halaman.

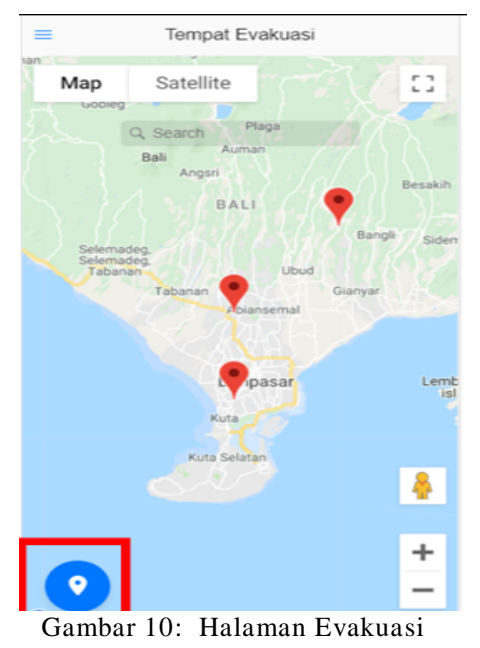

c) Pilih tempat lokasi yang diinginkan maka aplikasi akan otomatis memberikan rute terdekat ke lokasi tersebut seperti pada Gambar 11.

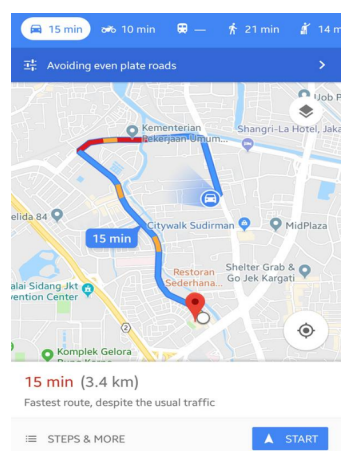

Gambar 11: Navigasi ke Tempat Evakuasi

p-ISSN:1693 - 2951; e-ISSN: 2503-2372

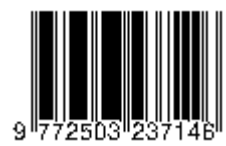


5) Fitur untuk mengetahui keadaan teman/kerabat dekat yang terdampak: Aplikasi ini dilengkapi dengan fitur untuk mengetahui keadaan teman atau kerabat dekat yang terdampak gempa bumi. Uji coba fitur ini yaitu sebagai berikut.

a) Teman atau kerabat mendapatkan notifikasi keadaan pengguna yang terdampak gempa bumi seperti pada Gambar 12.

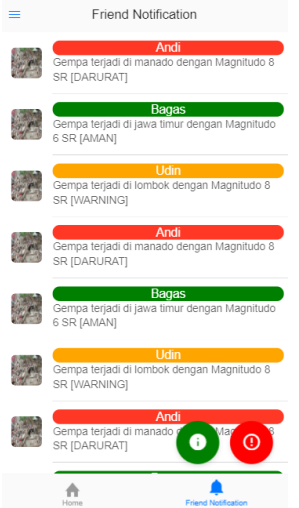

Gambar 12: Notifikasi Teman atau Kerabat yang Terdampak Gempa

b) Klik salah satu pengguna yang ada pada list tersebut untuk melihat posisi pengguna dan radius gempa seperti pada Gambar 13

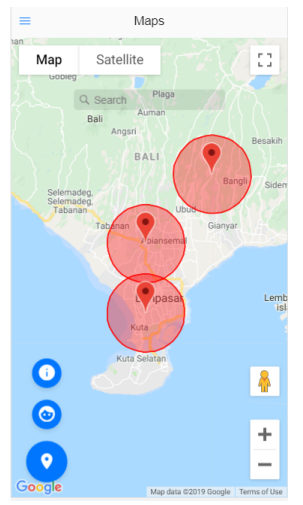

Gambar 13: Halaman posisi pengguna yang terdampak gempa

\section{KESIMPULAN}

Penelitian ini membahas tentang pengembangan Aplikasi Peringatan, Pemberitahuan dan Mitigasi Gempa Bumi menggunakan API InaSAFE berbasis mobile hybrid. Aplikasi yang dihasilkan dapat memberikan peringatan (alert) saat terjadi gempa bumi, memberi pemberitahuan kepada teman atau kerabat dekat tentang kondisi pengguna yang terdampak gempa bumi dan mengarahkan pengguna ke tempat evakuasi yang dekat dengan lokasinya. Data realtime gempa bumi didapatkan dari API InaSAFE dalam bentuk JSON yang direquest secara terjadwal menggunakan scheduler. Notifikasi yang dikirimkan oleh aplikasi dikembangkan menggunkan Firebase Push Notification, sedangkan untuk memetakan tempat evakuasi dan navigasi menggunakan Google Maps API. Aplikasi yang dihasilkan dapat berjalan di berbagai platform (cross platform) karena dikembangkan dengan teknologi hybrid menggunakan framework Cordova dan Onsen UI.

\section{REFERENSI}

[1] N. Djauhari, Geologi Lingkungan, Gaha Ilmu, Yogyakarta, 2006.

[2] BNPB (2019). Data Informasi Bencana Indonesia (DIBI). [Online]. Available : http://dibi.bnpb.go.id

[3] R. Mochammad, Application Early Warning System In Indonesia, Badan Meteorologi, Klimatologi, dan Geofisika (BMKG), 2013.

[4] I. Tommy, Mitigasi Gempa dan Tsunami di Daerah Perkotaan, Seminar Bidang Kerekayasaan Fatek-Unsrat, 2016.

[5] M. D. Kohler et al, "Earthquake Early Warning ShakeAlert System: West Coast Wide Production Prototype", Seismological Research Letters, vol. 89, no. 1, pp. 99-105, 2018.

[6] C. S. Elizabeth et al, "Eartquake Early Warning ShakeAlert System: Testing and Certification Platform", Seismological Research Letters, vol. 20, no. 20, pp. 1-10, 2017.

[7] E. Budiyanto, Sistem Informasi Geografis dengan Quantum GIS, Andi, Yogyakarta, 2016.

[8] Disaster Management Innovation \& Humanitarian OpenStreetMap Team, Analisis Data Menggunakan QGIS dan InaSAFE, Public Domain, 2015.

[9] K. R. Dwi, "Manajemen Rute Evakuasi Bencana Tsunami di Kota Palu Menggunakan Arccasper”, Universitas Hasanudin, 2012.

[10] Karyono et al, Warning Receiver System Dalam Penyebaran Peringatan Dini Tsunami di Tingkat Daerah di Indonesia, Badan Meteorologi, Klimatologi, dan Geofisika (BMKG), 2012.

[11] Humanitarian OpenStreetMap Team, Pengembangan Skenario untuk Rencana Kontinjensi Unit 2, Public Domain, 2015.

[12] R. M. de A. Paulo and A. B. Adriano, "Cross Platform App A Comparative Study", International Journal of Computer Science \& Information Technology, vol. 7, no. 1, pp. 33-40, 2015.

[13] R. Andre and R. Alberto, "Survey on Cross-Platform and Languages for Mobile Apps", $8^{\text {th }}$ International Conference on the Quality of Information and Communication Technology, 2012.

[14] P. W. Buana et al, "Real Time Trans Bus Tracking and Passenger Information System", International Journal of Software Engineering and Its Apllication, vol. 10, no. 9, pp. 35-50, 2016.

[15] E. Petroutsos, Google Maps, McGraw-Hill, ISBN:9780071823043, 2014.

[16] O. Suryana, Server dan Web Server, ozs.web.id, 2013.

[17] J. Herlian, Perancangan Mobile POS (Point of Sale) Dengan Menggunakan Restfull Web Services, UIB Repository, 2015.

[18] Z. Sonia, B. Lotfi and M. Abdellatif, "Priority based round robin (PBRR) CPU scheduling algorithm”, vol. 9, no. 1, pp. 190-202, 2018.

[19] Longitudestore (2019). The Haversine Formula. [Online]. Available : http://www.longitudestore.com/haversine-formula.html

[20] I. Sommerville, Software Engineering $9^{\text {th }}$ Edition, Addison-Welsey, 2011 